\title{
Mutucas (Diptera: Tabanidae) do estado do Paraná, Brasil: chave de identificação pictórica para subfamílias, tribos e gêneros
}

\author{
Mauren Turcatel ${ }^{1,3}$, Claudio José Barros de Carvalho ${ }^{1}$ \& José Albertino Rafael ${ }^{2}$ \\ Biota Neotropica v7 (n2) \\ http://www.biotaneotropica.org.br/v7n2/pt/abstract?identification-key+bn05007022007
}

\author{
Recebido em 27/03/07 \\ Versão reformulada recebida em 29/06/07 \\ Publicado em 31/07/07
}

\author{
${ }^{1}$ Departamento de Zoologia, Universidade Federal do Paraná, \\ CP 19020,CEP 81531-980, Curitiba,PR, Brasil,e-mail: cjbcarva@ufpr.br \\ ${ }^{2}$ Instituto Nacional de Pesquisas da Amazônia \\ CP 478, CEP 69011-970, Manaus, AM, Brasil, e-mail: jarafael@inpa.gov.br, http://www.inpa.gov.br \\ ${ }^{3}$ Autor para correspondência: Mauren Turcatel, e-mail: biomaureen@gmail.com
}

\begin{abstract}
Turcatel, M., Carvalho, C.J.B. \& Rafael, J.A. Horse flies (Diptera: Tabanidae) of Paraná State, Brazil: pictorial identification key for subfamilies, tribes and genera. Biota Neotrop. May/Aug 2007 vol. 7, no. 2. http://www.biotaneotropica.org.br/v7n2/pt/abstract?identification-key+bn05007022007. ISSN 1676-0603.

A survey of Tabanid species with occurrence in Paraná State was done in this paper, based on literature, records of the Collection of Entomology Padre Jesus Santiago Moure deposited in the Department of Zoology of the Federal University of Paraná (DZUP), records of the Museum of Zoology of the University of São Paulo (MZUSP) and on samplings done during the first year of the Project "Survey of the entomological fauna in Paraná State" (PROFAUPAR). A pictorial identification key for subfamilies, tribes and genera from Paraná was elaborated. Schematic drawings to illustrate the characters of genera have been done, corresponding to the morphology of head, wing, abdomen and legs. There are 68 species registered, distributed in 23 genera, six tribes and three subfamilies; 28 species are newly recorded for this State.

Keywords: horse fly, deer fly, taxonomy, pictorial key.

\section{Resumo}

Turcatel, M., Carvalho, C.J.B. \& Rafael, J.A. Mutucas (Diptera: Tabanidae) do estado do Paraná, Brasil: chave de identificação pictórica para subfamílias, tribos e gêneros. Biota Neotrop. May/Aug 2007 vol. 7, no. 2. http://www.biotaneotropica.org.br/v7n2/pt/abstract?identification-key+bn05007022007. ISSN 1676-0603.

Foi realizado um levantamento das espécies de Tabanidae ocorrentes em todo o Estado do Paraná, com base em dados da literatura, registros da Coleção de Entomologia Pe. Jesus Santiago Moure depositada no Departamento de Zoologia da Universidade Federal do Paraná (DZUP), registros do Museu de Zoologia da Universidade de São Paulo (MZUSP) e em coletas realizadas durante o primeiro ano do Projeto "Levantamento da fauna entomológica no Estado do Paraná" (PROFAUPAR). Foi elaborada uma chave de identificação pictórica para subfamílias, tribos e gêneros ocorrentes no Paraná. Foram confeccionados desenhos esquemáticos dos caracteres diagnósticos dos gêneros, correspondendo à morfologia da cabeça, asa, abdômen e pernas. São registradas 68 espécies, distribuídas em 23 gêneros, seis tribos e três subfamílias; 28 espécies foram registradas pela primeira vez no estado.
\end{abstract}

Palavras-chave: mutuca, botuca, taxonomia, chave pictórica. 


\section{Introdução}

Os Tabanidae são moscas cosmopolitas, conhecidos vulgarmente no Brasil como mutucas ou botucas. Os machos adultos alimentam-se de néctar (Roberts 1967, Magnarelli et al. 1979) e as fêmeas da maioria das espécies necessitam de proteína animal presente no sangue para a maturação dos folículos embrionários e oviposição. Devido ao comportamento hematófago das fêmeas, constituem um grupo de grande importância na transmissão mecânica de agentes patogênicos para animais silvestres e domésticos (Krinsky 1976), podendo afetar também ao homem. Bactérias, vírus, rickettsia, protozoários e vermes filarióideos podem ser transmitidos por tabanídeos, causando doenças como antraz, tularemia, anaplasmose, febre q, várias formas de tripanossomíases e filarioses (Pechuman \& Teskey 1981).

Tabanídeos adultos variam de 6 a $30 \mathrm{~mm}$ de comprimento; possuem a cabeça mais larga que o tórax, aparelho bucal tipo picador-sugador e antenas relativamente longas. A oviposição ocorre em ambientes aquáticos ou semi-aquáticos, propícios ao desenvolvimento das larvas que, geralmente carnívoras, alimentam-se de pequenos invertebrados de água doce. O tempo de desenvolvimento larval pode variar de quase um ano até mais de dois anos, enquanto o período de pupação dura de uma a duas semanas (Pechuman \& Teskey 1981). $\mathrm{O}$ adulto vive pouco tempo, dificilmente completando o terceiro e mais raramente o quarto ciclo gonotrófico, portanto, dificilmente ultrapassa dois meses (Rafael \& Charlwood 1980).

A família Tabanidae possui 4.300 espécies descritas, distribuídas em 137 gêneros. Atualmente, são listadas 1.172 espécies em 65 gêneros na região Neotropical, representando 27,3\% das espécies válidas em todo o mundo (Fairchild \& Burger 1994).

No Brasil, estudos sobre tabanídeos têm sido realizados freqüentemente no âmbito taxonômico, mas há poucos estudos sobre a biologia do grupo. No Paraná, França (1975) apresentou observações feitas quanto ao comportamento dos tabanídeos do Litoral e Primeiro Planalto paranaenses, abrangendo estudos sobre as épocas de maior atividade dos insetos, espécies que ocorrem em cada área do Leste paranaense, atividade diária das mutucas e preferências por cores das pelagens de equiinos e muares (iscas usadas para a captura). Dutra (1993) fez uma comparação da entomofauna da Ilha do Mel e das oito localidades de coleta do Projeto "Levantamento da Fauna Entomológica no Estado do Paraná" (PROFAUPAR) (Marinoni \& Dutra 1993). O autor comparou as áreas a partir de capturas com armadilha Malaise no período de um ano.

\section{Material e métodos}

Foi realizado o levantamento dos gêneros e das espécies de tabanídeos com registros no Estado do Paraná, a partir de dados dos trabalhos de França (1975) e Dutra (1993). Como parte deste levantamento inicial, os dados taxonômicos obtidos foram comparados com as espécies depositadas na Coleção de Entomologia Pe. Jesus Santiago Moure no Departamento de Zoologia da Universidade Federal do Paraná (DZUP).

Feita a comparação, foi realizado um estudo com o material do PROFAUPAR referente ao primeiro ano de coletas (agosto de 1986 a julho de 1987), em oito pontos do Estado do Paraná (Figura 1). Este material, conservado em álcool, foi então trazido para laboratório e triado. Os exemplares foram montados e identificados até gênero. $\mathrm{O}$ material foi depositado na Coleção de Entomologia Pe. Jesus Santiago Moure. Foi realizado, também, um levantamento das espécies coletadas no Estado do Paraná e depositadas no Museu de Zoologia de São Paulo (MZSP).

O material do DZUP e do MZSP possibilitou a elaboração da chave de identificação e a confecção das ilustrações, utilizando mi-

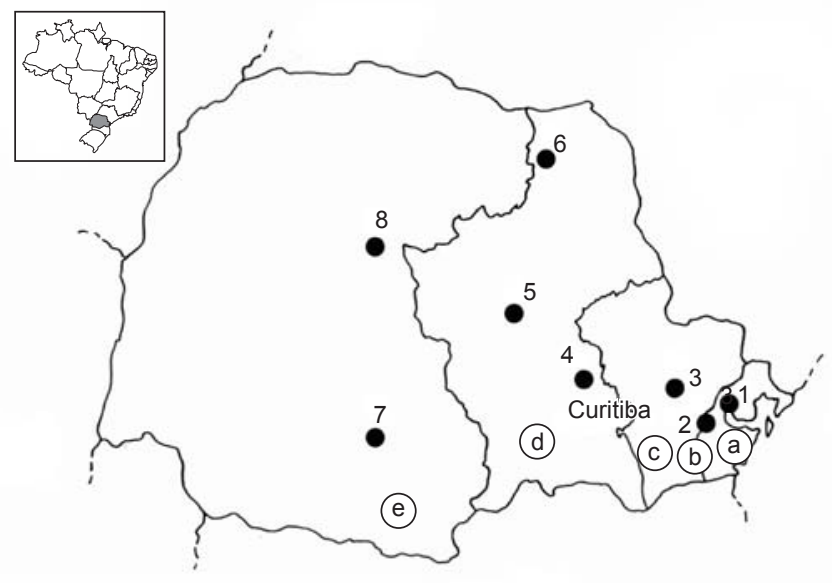

Figura 1. Estado do Paraná. Locais de coleta. 1) Antonina (Sapitanduva) $25^{\circ} 25^{\prime}$ 59" S e $48^{\circ} 42^{\prime} 48^{\prime \prime}$ W; 2) São José dos Pinhais (Serra do Mar) 25 34'57"

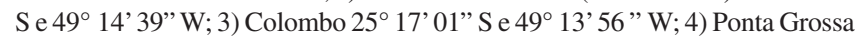
(Vila Velha) $25^{\circ} 05^{\prime} 53^{\prime \prime} \mathrm{S}$ e 5009' 35" W; 5) Telêmaco Borba (Reserva Biológica Klabin) 2420'03" S e 50 37' 27' W; 6) Jundiaí do Sul (Fazenda Monte Verde) $23^{\circ} 26^{\prime} 10^{\prime \prime}$ S e 50 14' 55' W; 7) Guarapuava (Santa Clara) 25 22' 54"'

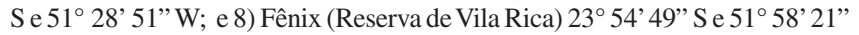
W. $a=$ Zona Litorânea; $b=$ Serra do Mar; $\mathrm{c}=$ Primeiro Planalto; $\mathrm{d}=$ Segundo Planalto; e e = Terceiro Planalto. (Marinoni \& Dutra 1993).

Figure 1. State of Paraná. Sampling localities. 1) Antonina (Sapitanduva) $25^{\circ} 25^{\prime} 59^{\prime \prime} \mathrm{S}$ and $48^{\circ} 42^{\prime} 48^{\prime \prime} \mathrm{W}$; 2) São José dos Pinhais (Serra do Mar Mountains) $25^{\circ} 34^{\prime} 57^{\prime \prime} \mathrm{S}$ and $49^{\circ} 14^{\prime} 39^{\prime \prime} \mathrm{W}$; 3) Colombo $25^{\circ} 17^{\prime} 01^{\prime \prime} \mathrm{S}$ and $49^{\circ}$ 13' 56" W; 4) Ponta Grossa (Vila Velha) 250 05' 53" S and 50 09'35" W; 5) Telêmaco Borba (Klabin Biological Reserve) 24 20'03' S and 50 37' 27' W; 6) Jundiaí do Sul (Monte Verde Farm) 23 26' 10" S and 50 14' 55" W; 7) Guarapuava (Santa Clara) 25 $5^{\circ} 22^{\prime} 54^{\prime \prime} \mathrm{S}$ and $51^{\circ} 28^{\prime} 51^{\prime \prime} \mathrm{W}$; (8) Fênix (Vila Rica Reserve) $23^{\circ} 54^{\prime} 49^{\prime \prime} \mathrm{S}$ and $51^{\circ} 58^{\prime} 21^{\prime \prime} \mathrm{W}$. a = Littoral Zone; b = Serra do Mar Mountains; $\mathrm{c}=$ First Plateau; $\mathrm{d}=$ Second Plateau; and e = Third Plateau. (Marinoni \& Dutra 1993).

croscópio estereoscópico e microscópio óptico, ambos com câmara clara embutida. As ilustrações foram digitalizadas e editadas com a utilização de programas de computador. Foram confeccionados desenhos dos caracteres diagnósticos dos gêneros, correspondendo à morfologia externa da cabeça, asa, abdômen e pernas.

A terminologia utilizada segue aquela proposta por McAlpine (1981) e Pechuman \& Teskey (1981). A classificação segue Fairchild \& Burger (1994). A identificação de subfamílias, tribos e gêneros foi feita seguindo Fairchild (1969) e Coscarón \& Papavero (1993). Para as diagnoses específicas, foram utilizadas as descrições originais, redescrições e revisões de gênero, além de comparações diretas com espécimes de referência do DZUP, MZSP e do Instituto Nacional de Pesquisas da Amazônia (INPA). A chave de identificação pictórica foi feita seguindo o modelo de Couri \& Pont (1999).

\section{Resultados}

Os resultados consistem no levantamento de 68 espécies com registros no Paraná; 28 novos registros de espécies para o estado; uma chave de identificação pictórica para as três subfamílias, seis tribos e 23 gêneros de tabanídeos com 43 ilustrações no total; diagnoses para subfamílias, tribos e gêneros; dados sobre distribuição das espécies, de acordo com Fairchild \& Burger (1994); e dados sobre o material examinado. 


\section{Chave de identificação para subfamílias, tribos e gêneros de Tabanidae do estado do Paraná, Brasil}

1. Flagelo com placa basal (fusão dos primeiros flagelômeros) com (Figura 2a) ou sem (Figura 2b) espinho dorsal, e quatro ou menos flage-

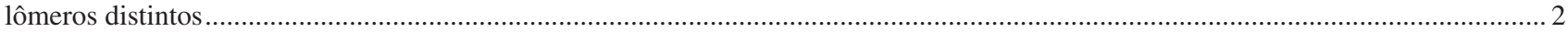
$1^{\prime}$. Flagelo geralmente com sete ou oito flagelômeros, raramente com placa basal (Figura 3) Subfamília Pangoniinae......................... 3

2 (1). Ocelos conspícuos (Figura 4)...

2’. Ocelos inconspícuos ou ausentes (Figura 5)

Subfamília Chrysopsinae - Tribo Chrysopsini - Gênero Chrysops Subfamília Tabaninae

3 (1'). Face inflada, cônica, fortemente projetada para frente; probóscide geralmente excedendo o comprimento da cabeça (Figura 6)...........

$3^{\prime}$. Face não como o descrito acima, probóscide não excedendo o comprimento da cabeça (Figura 7) …………………...................5

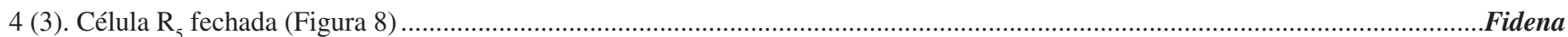

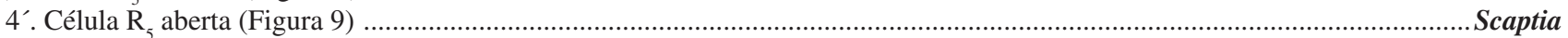

5 (3’). Peças bucais vestigiais (Figura 10)

Tribo Scepsidini - Gênero Scepsis

5'. Peças bucais bem desenvolvidas (Figura 11) Tribo Pangoniini

... 6

6 (5'). Flagelo com oito flagelômeros (Figura 12)

Esenbeckia

6'. Flagelo com sete flagelômeros (Figura 13)

Protosilvius

7 (2'). Basicosta sem cerdas, se presentes, estas menos densas que nas adjacências da veia costal (Figura 14) Tribo Diachlorini ............... 8 7’. Basicosta com cerdas densas, tão densas quanto nas adjacências da veia costal (Figura 15) Tribo Tabanini ................................22

8 (7). Labela não membranosa, totalmente ou parcialmente esclerotinizada (Figura 16) …............................................................. 9

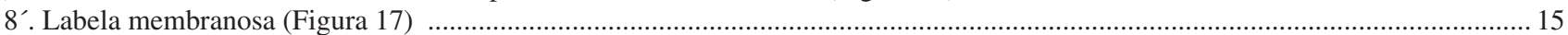

9 (8). Base do flagelo sem espinho (Figura 18a), no máximo com angulação obtusa dorsal (Figura 18b) …......................................... 10

$9^{\prime}$. Base do flagelo com espinho agudo ou prolongamento dorsal (Figura 19) .......................................................................... 12

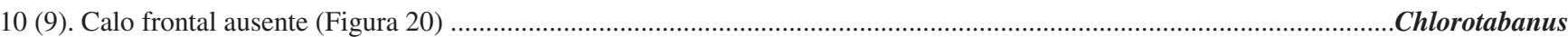

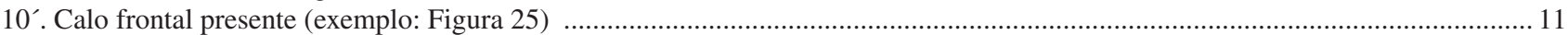

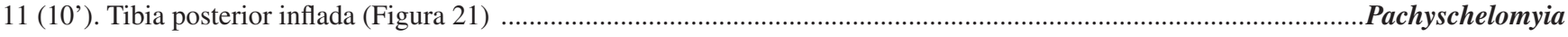

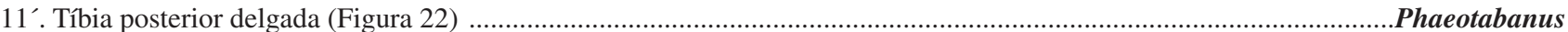

12 (9'). Abdômen com constrição entre os segmentos 2 e 3; espécimes com aspecto semelhante a vespa (Figura 23) ................Acanthocera

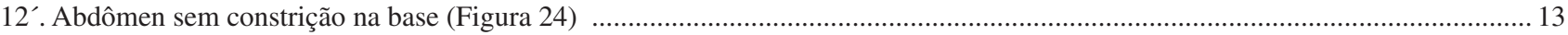

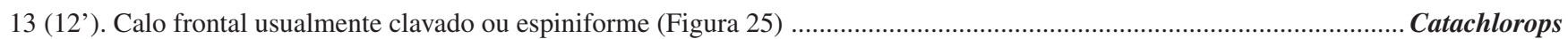

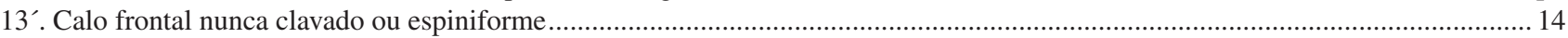

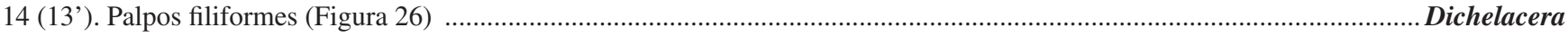

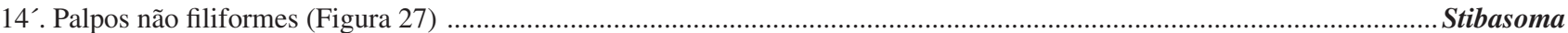

15 (8'). Célula discal estreitada medianamente pela curvatura da veia $\mathrm{M}_{3}$ (Figura 28) ........................................................... Lepiselaga

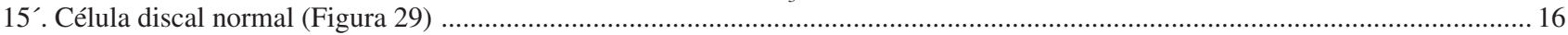

$16\left(15^{\prime}\right)$. Asa com manchas circulares marrons em todas as intersecções das veias (Figura 30) ..............................................Anaerythrops

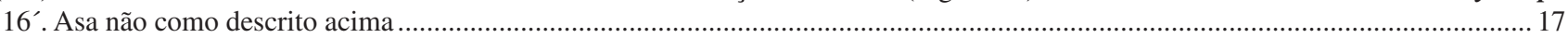

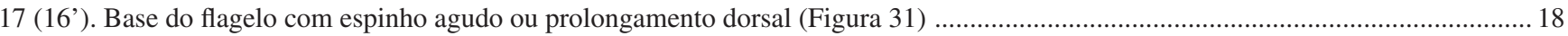

17’. Base do flagelo sem espinho (Figura 32a), no máximo com angulação obtusa dorsal (Figura 32b) ........................................... 19

18 (17). Asa hialina, com intersecções das veias enfuscadas (Figura 33) .......................................................................................typommisa 18’. Asa não hialina, com manchas escuras (Figura 34) .............................................................................................. Dicladocera

19 (17’). Palpos castanho-escuros, inflados e brilhantes (Figura 35) ….........................................................................Pseudacanthocera

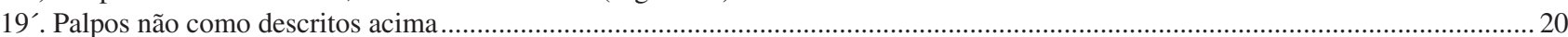

20 (19). Asa hialina com pterostigma e veia costal castanho-escuros (Figura 36) ................................................................eucotabanus

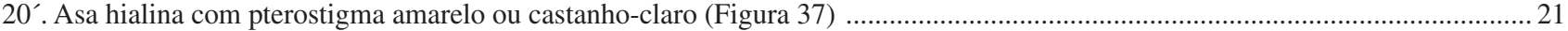

21 (20’). Face lisa e brilhante, inflada, bem distinta da parafaciália (Figura 38) .........................................................................Diachlorus

$21^{\prime}$. Face pruinosa, pouco distinta da parafaciália (Figura 39) .......................................................................................tenotabanus

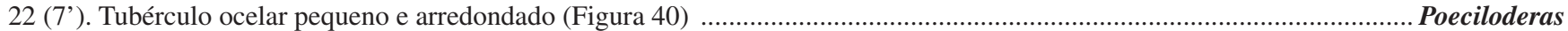

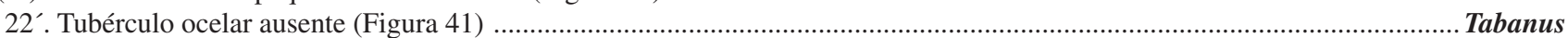


(a)

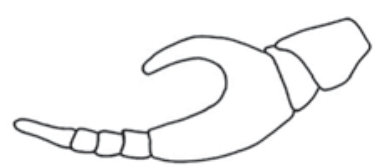

(b)

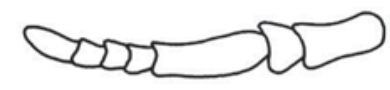

Figura 2. a) Flagelo com espinho dorsal e b) Flagelo sem espinho dorsal.

Figure 2. a) Flagellum with dorsal tooth and b) Flagellum without dorsal tooth.

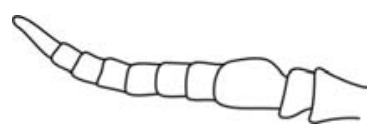

Figura 3. Flagelo com sete ou oito flagelômeros.

Figure 3. Flagellum of seven or eight anulli.

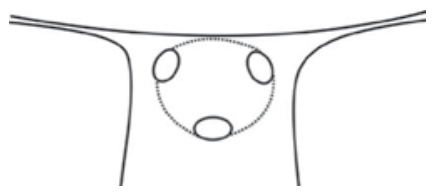

Figura 4. Ocelos presentes.

Figure 4. Ocelli present.

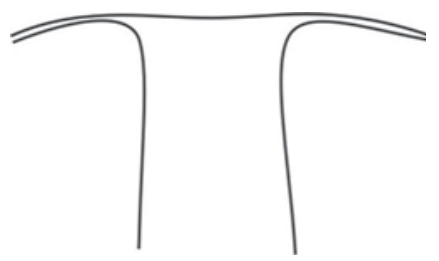

Figura 5. Ocelos ausentes.

Figure 5. Ocelli absent.

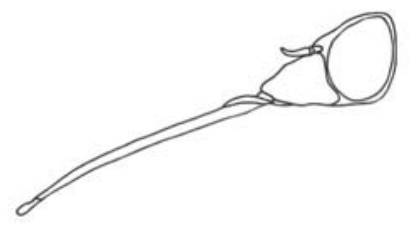

Figura 6. Face inflada.

Figure 6. Face inflated.

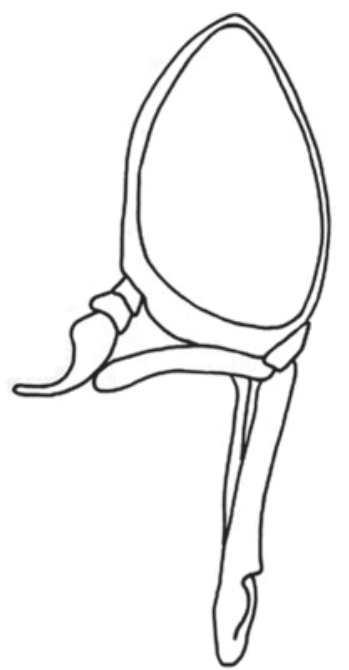

Figura 7. Face não inflada.

Figure 7. Face not inflated.

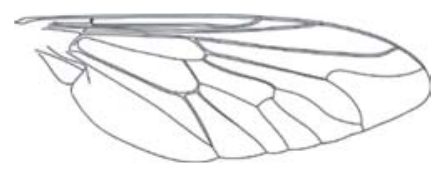

Figura 8. Célula $R_{5}$ fechada.

Figure 8. Cell $\mathrm{R}_{5}$ closed.

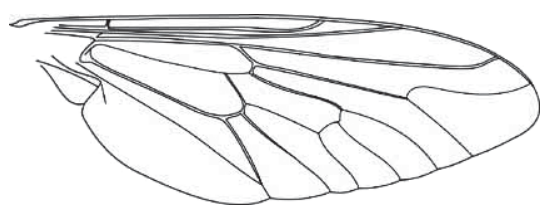

Figura 9. Célula $R_{5}$ aberta.

Figure 9. Cell $\mathrm{R}_{5}$ open.

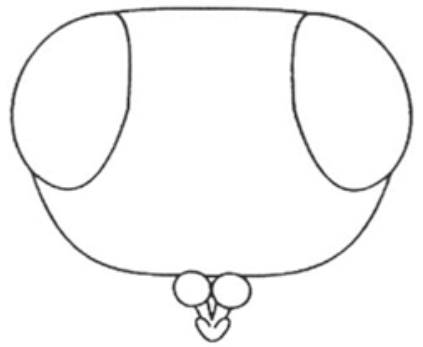

Figura 10. Peças bucais vestigiais.

Figure 10. Mouthparts vestigial. 


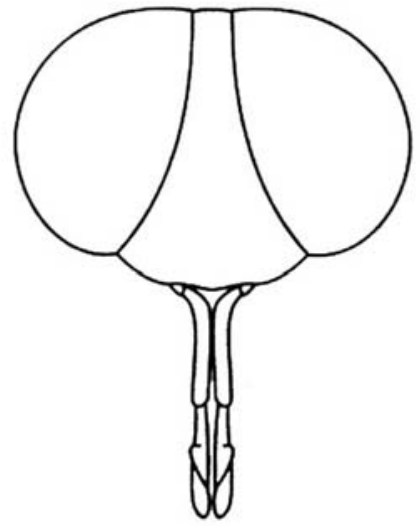

Figura 11. Peças bucais bem desenvolvidas.

Figure 11. Mouthparts well developed.

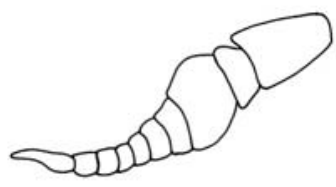

Figura 12. Flagelo com oito flagelômeros.

Figure 12. Flagellum of eight anulli.

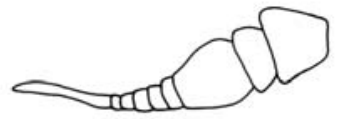

Figura 13. Flagelo com sete flagelômeros.

Figure 13. Flagellum of seven anulli.

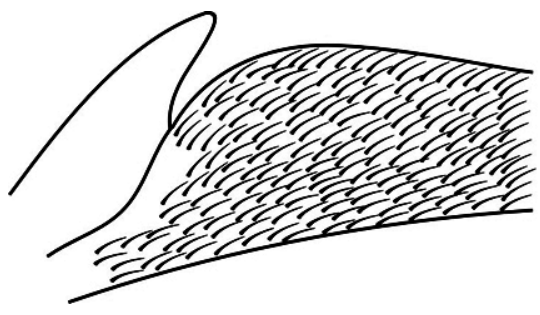

Figura 14. Basicosta sem cerdas.

Figure 14. Basicosta without setae.

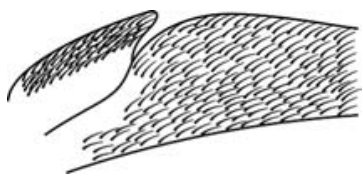

Figura 15. Basicosta com cerdas.

Figure 15. Basicosta with setae.

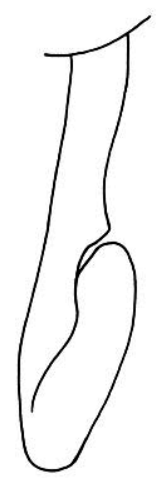

Figura 16. Labela esclerotinizada.

Figure 16. Labela sclerotized.

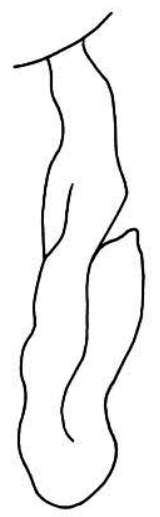

Figura 17. Labela membranosa.

Figure 17. Labela pollinose.

(b)

(a)
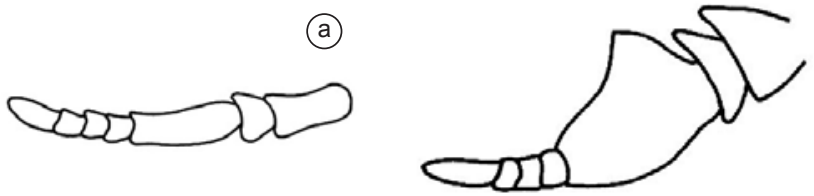

Figura 18. a) Base do flagelo sem espinho e b) Base do flagelo com angulação.

Figure 18. a) Flagellum base without dorsal tooth and b) Flagellum base angled above.

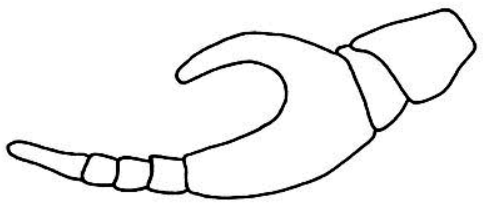

Figura 19. Base do flagelo com espinho.

Figure 19. Flagellum base with dorsal tooth. 


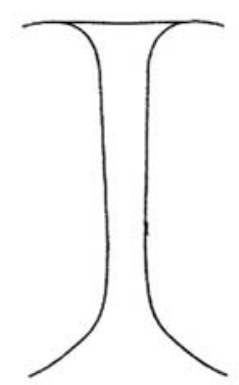

Figura 20. Calo frontal ausente.

Figure 20. Frontal callus absent.

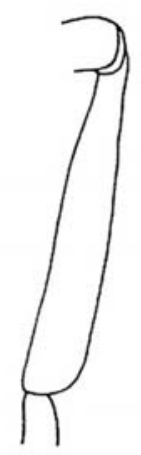

Figura 21. Tíbia posterior inflada.

Figure 21. Hind tibiae inflated.

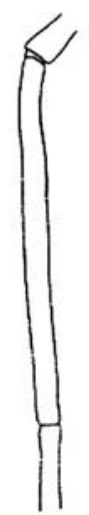

Figura 22. Tíbia posterior delgada.

Figure 22. Hind tibiae slender.

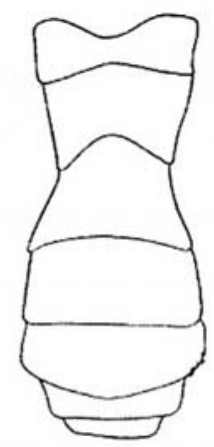

Figura 23. Abdômen com constrição na base.

Figure 23. Abdomen constricted basally.

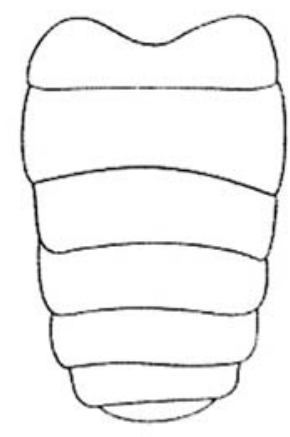

Figura 24. Abdômen sem constrição na base.

Figure 24. Abdomen not constricted basally.

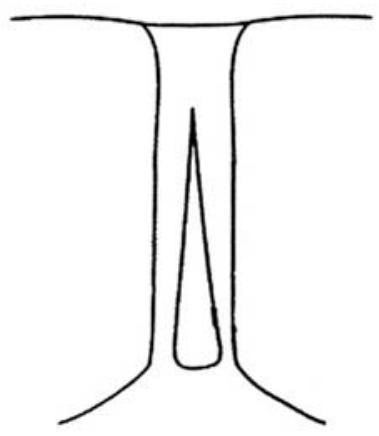

Figura 25. Calo frontal clavado ou espiniforme.

Figure 25. Frontal callus clavate or ridge-like.

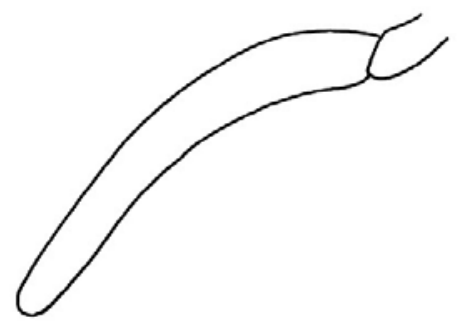

Figura 26. Palpos filiformes.

Figure 26. Palpi slender.

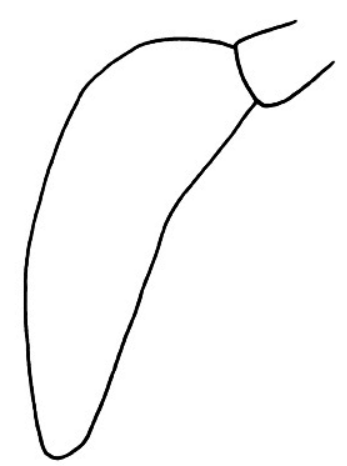

Figura 27. Palpos não filiformes.

Figure 27. Palpi not slender. 


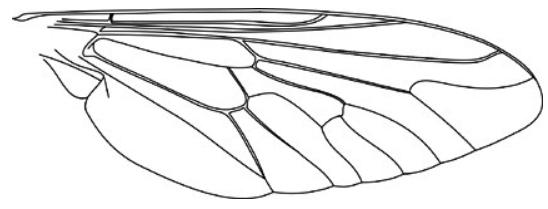

Figura 28. Célula discal estreitada medianamente.

Figure 28. Discal cell narrowed in the middle.

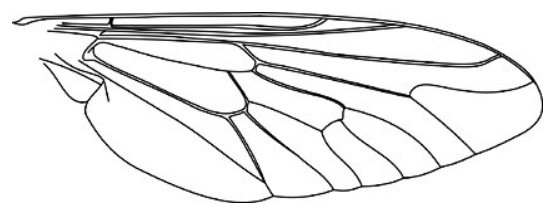

Figura 29. Célula discal normal.

Figure 29. Discal cell normal.

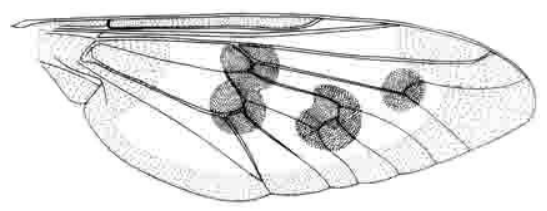

Figura 30. Asa com manchas circulares marrons.

Figure 30. Wing with circular brown spots.

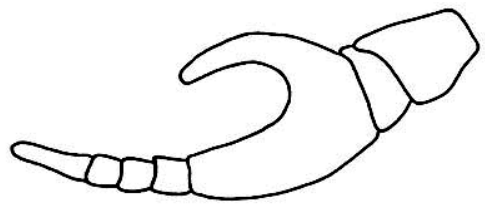

Figura 31. Base do flagelo com espinho.

Figure 31. Third antennal segment with dorsal tooth.

(a)

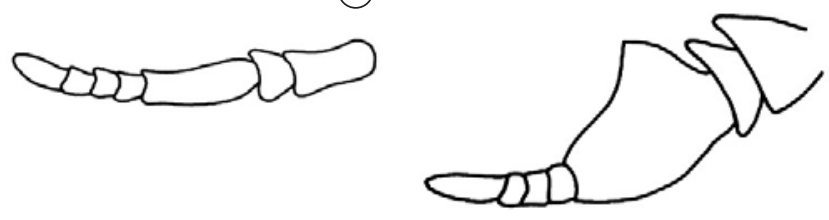

Figura 32. a) Base do flagelo sem espinho e b) Base do flagelo com angulação.

Figure 32. a) Flagellum base without dorsal tooth and b) Flagellum base agled above.

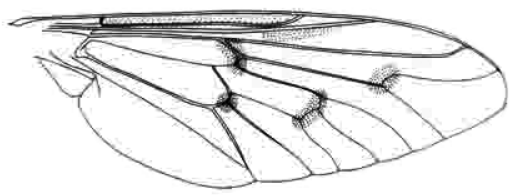

Figura 33. Asa hialina.

Figure 33. Wing hyaline

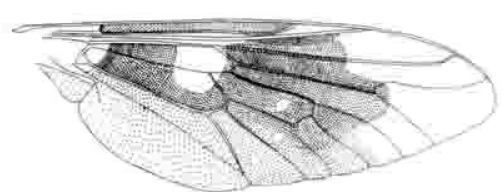

Figura 34. Asa não hialina.

Figure 34. Wing marked.

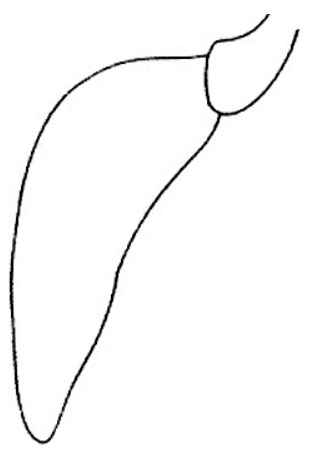

Figura 35. Palpos inflados.

Figure 35. Palpi inflated.

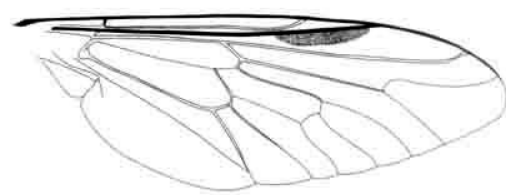

Figura 36. Pterostigma castanho-escuro.

Figure 36. Pterostigma dark brown.

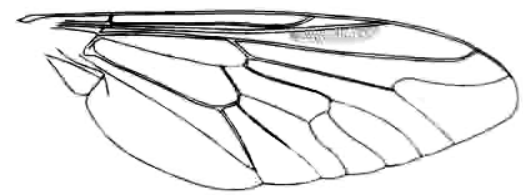

Figura 37. Pterostigma amarelo ou castanho-claro.

Figure 37. Pterostigma yellow or light brown.

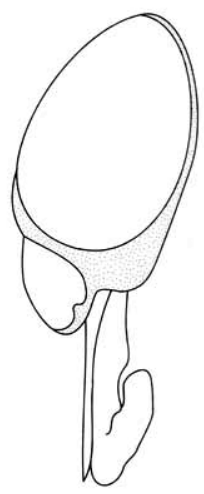

Figura 38. Face lisa e brilhante.

Figure 38. Face shiny. 


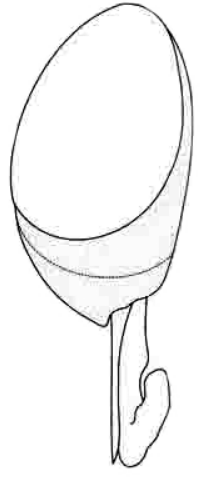

Figura 39. Face pruinosa.

Figure 39. Face pruinose.

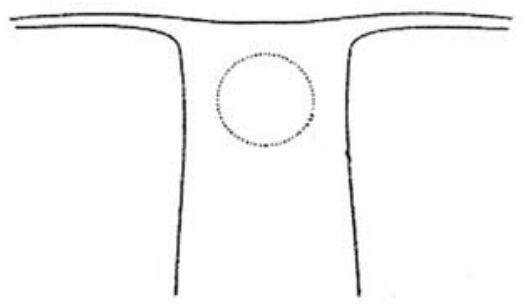

Figura 40. Tubérculo ocelar.

Figure 40. Ocellar tubercle.

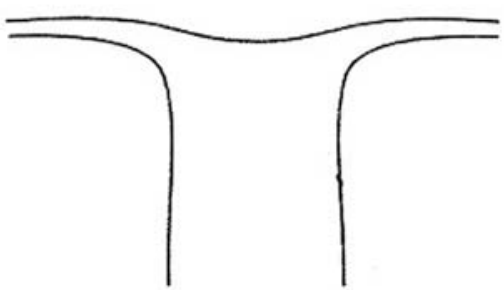

Figura 41. Tubérculo ocelar ausente.

Figure 41. Ocellar tubercle absent.

\section{Lista de reconhecimento de subfamílias, tribos e gêneros, com dados sobre distribuição das espécies Subfamília Pangoniinae}

Flagelo geralmente com sete ou oito flagelômeros, raramente com placa basal; ocelos e espinhos apicais na tíbia ausentes; olhos sem padrão de colorido em vida.

\section{Tribo Pangoniini}

Olhos glabros; forte apêndice na forquilha da veia $\mathrm{R}_{4}$; face não produzida conicamente e probóscide dificilmente ultrapassando o comprimento da cabeça.

\section{Gênero Esenbeckia Rondani, 1863}

Espécies médias a grandes, delgadas a robustas; olhos com cerdas muito curtas, claras e esparsas; antena com flagelo estreitado distalmente; corpo recoberto por cerdas curtas; asa geralmente com padrão de colorido; labela geralmente compacta; fronte geralmente estreita.

\section{Esenbeckia esenbeckii esenbeckii (Wiedemann, 1830)}

Distribuição geográfica: Brasil (Minas Gerais, Paraná); Paraguai; Argentina; Uruguai.

Material examinado: Paraná: Ponta Grossa, Lageado, 22/II/1946, sem coletor (1 fêmea, DZUP).

Nota: Primeiro registro no estado do Paraná.

\section{Esenbeckia esenbeckii biscutellata Lutz, 1909}

Distribuição geográfica: Brasil (Paraná); Paraguai.

Material examinado: Paraná: Guarapuava, sem data, U. M. Kurowski leg. (1 fêmea, DZUP); idem, sem data, O. Rodrigues leg. (1 fêmea, DZUP). Palmeira, 20/I/1968, Moure \& Giacomel leg. (4 fêmeas, DZUP); idem, 08/II/1976, Moure leg. (1 fêmea, DZUP).

Nota: Primeiro registro no estado do Paraná.

\section{Esenbeckia fenestrata Lutz, 1909} na).

Distribuição geográfica: Brasil (Minas Gerais à Santa Catari-

Material examinado: Paraná: Curitiba, sem data, U. M. Kurowski leg. (1 macho, DZUP).

\section{Esenbeckia fuscipennis (Wiedemann, 1828)} na).

Distribuição geográfica: Brasil (Minas Gerais à Santa Catari-

Material examinado: Paraná: Ponta Grossa, 23/II/1945, F. A. Justus leg. (1 fêmea, DZUP).

\section{Esenbeckia lugubris (Macquart, 1838)}

Distribuição geográfica: Brasil (São Paulo, Paraná); Bolívia; Paraguai; Argentina (Chaco, Misiones).

Material examinado: Paraná: Foz do Iguaçu, 5/XII/1966, Exc. Dept. ZOO (1 fêmea, DZUP).

Nota: Primeiro registro no estado do Paraná.

\section{Esenbeckia tristis Kröber, 1931}

Distribuição geográfica: Brasil (Paraná, Santa Catarina, Rio Grande do Sul); Paraguai.

Material examinado: Paraná: Foz do Iguaçu, 5/XII/1966, Exc. Dept. ZOO (1 fêmea, DZUP).

Nota: Primeiro registro no estado do Paraná.

\section{Gênero Protosilvius Enderlein, 1922}

Espécies pequenas; asas longas; labela membranosa; fronte estreita; calo frontal ausente; tubérculo ocelar proeminente, com três ocelos bem desenvolvidos; olhos glabros; flagelo com 4 a 7 flagelômeros.

\section{Protosilvius termitiformis Enderlein, 1922}

Distribuição geográfica: Brasil (Minas Gerais, Paraná).

Material examinado: Paraná: Foz do Iguaçu, sem data, S. Laroca leg. (2 fêmeas, DZUP).

Nota: Primeiro registro no estado do Paraná.

\section{Tribo Scepsidini}

Tribo com um único gênero, Scepsis, monotípico para S. nivalis Walker, 1850.

\section{Gênero Scepsis Walker, 1850}

Moscas brancas e delgadas; asas claras; peças bucais vestigiais; ambos os sexos com fronte larga e sem calo frontal. Únicos tabanídeos cujas fêmeas não possuem hábito hematófago, sendo exclusivamente fitófagas. 


\section{Scepsis nivalis Walker, 1850}

Distribuição geográfica: Brasil (Rio de Janeiro à Santa Catarina); Argentina; Uruguai.

Material examinado: Paraná: Guarapuava, sem data, U. M. Kurowski leg. (1 fêmea, DZUP).

Nota: O gênero Scepsis Walker possui apenas uma espécie descrita, Scepsis nivalis, que ocorre nas areias de praia do sul do Rio de Janeiro até, provavelmente, o Norte da Argentina (Fairchild, 1969). Os dados presentes na etiqueta do espécime de Scepsis nivalis depositado no DZUP indicam como local de coleta a cidade de Guarapuava, no interior do Estado do Paraná; não é possível inferir se a espécie realmente ocorre no interior do estado ou se os dados de etiqueta estão errados.

\section{Tribo Scionini}

Olhos usualmente pilosos; face geralmente inflada e cônica; probóscide muito longa, excedendo o comprimento da cabeça.

\section{Gênero Fidena Walker, 1850}

Antena estreitada distalmente, fronte paralela; face protuberante; probóscide longa; olhos com cerdas longas e densas; célula $\mathrm{R}_{5}$ fechada ou estreitada, raramente aberta.

\section{Fidena adnaticornis Castro, 1945}

Distribuição geográfica: Brasil (Goiás, Minas Gerais, Rio de Janeiro, São Paulo, Paraná).

Material examinado: Paraná: Deodoro, Banhado, X/1944, Hatschbach leg. (1 fêmea, MZSP).

Nota: Primeiro registro no estado do Paraná.

\section{Fidena brachycephala Kröber, 1931}

Distribuição geográfica: Brasil (Goiás ao Rio de Janeiro; Paraná).

Material examinado: Paraná: Campo Largo, 18/XII/1992, R. Bassi leg. (1 fêmea, DZUP); idem, 09/I/1993. (2 fêmeas, DZUP); idem, 08/VIII/1993 (4 fêmeas, DZUP).

Nota: Primeiro registro no estado do Paraná.

\section{Fidena campolarguensis Bassi, 1995}

Distribuição geográfica: Brasil (Paraná).

Nota: A espécie foi descrita com base em um espécime coletado em Campo Largo, Paraná (Bassi 1995), porém o material-tipo não foi encontrado na coleção Pe. Jesus Santiago Moure (DZUP) para análise.

\section{Fidena nigripes (von Röder, 1886)}

Distribuição geográfica: Brasil (Goiás à Santa Catarina, Minas Gerais e Rio Grande do Sul).

Material examinado: Paraná: Deodoro, Banhado, XI/1944, Hatschbach leg. (1 fêmea, MZSP).

\section{Fidena rufopilosus mirabilis Lutz, 1911}

Distribuição geográfica: Brasil (Espírito Santo, Rio de Janeiro, São Paulo, Paraná).

Nota: A ocorrência da espécie no estado foi registrada por Carrera \& Lane (1945), porém o material não foi encontrado na coleção Pe. Jesus Santiago Moure (DZUP) para análise.

\section{Fidena sorbens (Wiedemann, 1828)}

Distribuição geográfica: Brasil (Mato Grosso, São Paulo ao Rio Grande do Sul); Bolívia; Paraguai; Argentina (Entre Rios, Misiones); Uruguai.

Material examinado: São Paulo: Rio Paraná, Porto Cabral, 20-31/ III/1944, Travassos Filho, Carrera \& Dante leg. (1 fêmea, MZSP).

\section{Fidena venosa (Wiedemann, 1821)}

Distribuição geográfica: Brasil (Rio de Janeiro, São Paulo, Paraná).

Material examinado: Paraná: Engenheiro Lange, III/1942, Hatschbach leg. (1 fêmea, MZSP).

Nota: Primeiro registro no estado do Paraná.

\section{Gênero Scaptia Walker, 1850}

Probóscide curta e larga; fronte divergente abaixo; face não inflada, pilosa.

\section{Scaptia longipennis (Ricardo, 1902)}

Distribuição geográfica: Brasil (Minas Gerais à Santa Catarina); Argentina (Mendoza à Misiones).

Material examinado: Paraná: Ponta Grossa, XII/1948, sem coletor (1 fêmea, DZUP).

\section{Scaptia seminigra (Ricardo, 1902)}

Distribuição geográfica: Brasil (Minas Gerais, Espírito Santo, Rio de Janeiro, Paraná,).

Material examinado: Paraná: Morretes, V/1944, sem coletor (1 fêmea, MZSP).

Nota: Primeiro registro no estado do Paraná.

\section{Subfamília Chrysopsinae}

Espinhos apicais na tíbia e ocelos usualmente presentes, olhos freqüentemente com padrões de faixas ou manchas de cores contrastantes em vida.

\section{Tribo Chrysopsini}

Primeiro artículo antenal geralmente duas vezes mais longo do que largo; calo frontal tão ou mais largo do que alto; olhos salpicados, ou com um padrão específico de pontos e listras.

\section{Gênero Chrysops Meigen, 1800}

Espécies pequenas, comprimento entre 5,1 a $8,5 \mathrm{~mm}$; em vida, olhos com padrão de colorido complexo; fronte larga; três ocelos distintos; calo frontal geralmente inflado e largo; antena longa e cilíndrica; face geralmente brilhante; palpos inflados; labela geralmente parcialmente esclerotinizada; basicosta sem cerdas; asas com padrão de colorido complexo.

\section{Chrysops bulbicornis Lutz, 1911}

Distribuição geográfica: Colômbia (Antioquia, Choco); Brasil (São Paulo, Paraná); Peru; Bolívia; Paraguai.

Material examinado: Paraná: Foz do Iguaçu, 5/XII/1966, Exc. Dep. ZOO (2 fêmeas, DZUP).

Nota: Primeiro registro no estado do Paraná.

\section{Chrysops crucians Wiedemann, 1828}

Distribuição geográfica: Brasil (Bahia, Goiás, Rio de Janeiro, São Paulo, Paraná).

Material examinado: Paraná: Foz do Iguaçu, 10/XII1966, Exc. Dep. ZOO (13 fêmeas, DZUP).

Nota: Primeiro registro no estado do Paraná.

\section{Chrysops laetus Fabricius, 1805}

Distribuição geográfica: Suriname; Colômbia (Vaupes); Brasil (Rondônia, Paraná); Paraguai; Argentina (Misiones).

Material examinado: Paraná: Antonina, Res. Sapitanduva, 22/XII/1986, Lev. Ent. PROFAUPAR, Malaise (1 fêmea, DZUP). Curitiba, Represa de Piraquara II, 19/I/2000, C. J. B. de Carvalho leg. (4 fêmeas, DZUP).

Nota: Primeiro registro no estado do Paraná. 


\section{Chrysops leucospilus Wiedemann, 1828}

Distribuição geográfica: Panamá; Brasil; Paraguai.

Material examinado: Paraná: Antonina, Reserva Sapitanduva, 24/XI/1986, Lev. Ent. PROFAUPAR, Malaise (1 fêmea, DZUP). Campo Largo, 21/II/1992, R. Bassi leg. (2 fêmeas, DZUP). Fênix, Reserva Est. I.T.C.F., 17/XI/1986, Lev. Ent. PROFAUPAR, Malaise (1 fêmea, DZUP). Foz do Iguaçu, 10/XII/1966, Exc. Dept. ZOO leg. (1 fêmea, DZUP). Ponta Grossa, Vila Velha, Reserva IAPAR, BR 376, 16/III/1987, Lev. Ent. PROFAUPAR, Malaise (1 fêmea, DZUP).

\section{Chrysops peruvianus Kröber, 1925}

Distribuição geográfica: Peru; Brasil (Paraná).

Material examinado: Paraná: Foz do Iguaçu, 5/XII/1966, Exc. Dept. ZOO leg. (8 fêmeas, DZUP). Jundiaí do Sul, Fazenda Monte Verde, 12/I/1987, Lev. Ent. PROFAUPAR, Malaise (1 fêmea, DZUP).

Nota: Primeiro registro no estado do Paraná.

\section{Chrysops varians Wiedemann, 1828}

Distribuição geográfica: Venezuela; Colômbia; Brasil (Amapá ao Rio de Janeiro, Paraná); Argentina (Chaco, Entre Rios, Misiones).

Material examinado: Paraná: Campo Largo, 08/II/1992, R. Bassi leg. (1 fêmea, DZUP); idem, 12/II/1992 (5 fêmeas, DZUP). Curitiba, XII/1946, M. Linsing leg. (1 fêmea, DZUP).

Nota: Primeiro registro no estado do Paraná.

\section{Chrysops variegatus (DeGeer, 1776)}

Distribuição geográfica: Índia Ocidental; México; Cuba; Porto Rico; Brasil; Peru; Argentina.

Material examinado: Paraná: Fênix, Res. Est. I.T.C.F., 20/II/1987, Lev. Ent. PROFAUPAR, Lâmpada (1 fêmea, DZUP). Foz do Iguaçu, 3/XII/1966, Exc. Dept. ZOO leg. (3 fêmeas, DZUP). Telêmaco Borba, Res. Samuel Klabin, 20/X/1986, Lev. Ent. PROFAUPAR, Malaise (2 fêmeas, DZUP)

\section{Subfamília Tabaninae}

Ocelos funcionais ausentes, porém, ocelos vestigiais freqüentemente presentes. Espinho apical na tíbia ausente.

\section{Tribo Diachlorini}

Basicosta sem cerdas; antena raramente com menos de quatro flagelômeros, freqüentemente com espinho dorsal; vestígios de ocelos usualmente presentes; labela totalmente ou parcialmente esclerotinizada.

\section{Gênero Acanthocera Macquart, 1834}

Abdômen delgado e geralmente com constrição no extremo proximal, semelhantes a vespas (Hymenoptera); antena relativamente longa, flagelo maior que o escapo e o pedicelo juntos; papos delgados; labela parcialmente esclerotinizada; pernas geralmente bicoloridas; asas com basicosta nua e padrão de colorido complexo.

\section{Acanthocera aureoscutellata Henriques \& Rafael, 1992}

Distribuição geográfica: Brasil (Mato Grosso, Goiás, Minas Gerais, Rio de Janeiro, São Paulo, Paraná); Paraguai; Argentina (Corrientes).

Material examinado: Paraná: Guarapuava, sem data, G. Kurowski leg. (1 fêmea, DZUP). Ponta Grossa, Vila Velha, Reserva IAPAR - BR 376, 24/XI/1986, Lev. Ent. PROFAUPAR, Malaise (1 fêmea, DZUP).

\section{Acanthocera apicalis (Fairchild, 1939)}

Distribuição geográfica: Brasil (São Paulo, Paraná).
Material examinado: Paraná: Antonina, 28/II/1965, D. Urban leg. (1 fêmea, DZUP). S. José dos Pinhais, BR 277 km 54, 08/III/1985, C.I.I.F., Luminosa (1 fêmea, DZUP); idem, 13/III/1985 (1 fêmea, DZUP).

Nota: Primeiro registro no estado do Paraná.

\section{Acanthocera longicornis (Fabricius, 1755)}

Distribuição geográfica: Brasil (Minas Gerais, Espírito Santo, Rio de Janeiro, São Paulo, Paraná, Santa Catarina).

Material examinado: Paraná: Pontal do Sul, 05/XII/1992, R. Bassi leg. (12 fêmeas, DZUP).

Nota: Primeiro registro no estado do Paraná.

\section{Acanthocera steleiothorax (Barretto, 1947)}

Distribuição geográfica: Brasil (Paraná: Rio Papagaios).

Material examinado: Paraná: Campo Largo, III/1945, sem coletor (1 fêmea, MZSP).

\section{Acanthocera tenuicornis (Lutz, 1915)}

Distribuição geográfica: Brasil (Minas Gerais, São Paulo, Paraná, Santa Catarina)

Material examinado: Paraná: Quatro Barras, 06/II/1966, Pe. J. Moure leg. (1 fêmea, DZUP).

Nota: Primeiro registro no estado do Paraná.

\section{Gênero Anaerythrops Barretto, 1948}

Espécies semelhantes a Stenotabanus, mas com olhos bicoloridos e com áreas glabras na face; asas com manchas circulares marrons em torno de todas as intersecções das veias.

\section{Anaerythrops lanei Barretto, 1948}

Distribuição geográfica: Brasil (Rio de Janeiro, São Paulo, Paraná).

Material examinado: Paraná: Morretes (IAPAR), 18/I/1985, C.I.I.F. (Luminosa) (1 fêmea, DZUP). São José dos Pinhais, BR 277 $\mathrm{km}$ 54, 23/III/1985, C.I.I.F. (Luminosa) (10 fêmeas, DZUP).

Nota: Primeiro registro no Estado do Paraná.

\section{Gênero Catachlorops Lutz, 1911}

Fronte estreita; calo frontal usualmente espiniforme; primeiro flagelômero com espinho dorsal longo; palpo delgado a filiforme; tíbias delgadas; asas quase sempre com padrão de colorido, nunca totalmente hialina.

\section{Catachlorops fonsecai Barretto, 1946}

Distribuição geográfica: Brasil (Rio de Janeiro, São Paulo, Paraná).

Material examinado: São Paulo: Boracéia, I/1948, Travassos Filho leg. (1 fêmea, MZSP).

\section{Catachlorops furcatus (Wiedemann, 1828)}

Distribuição geográfica: Brasil (Paraná, Santa Catarina).

Material examinado: Paraná: Ilha do Mel, Praia Grande, 21/ X/1989, R. Dutra leg. (2 fêmeas, DZUP). Pontal do Sul, 07/III/1991, R. Bassi leg. (9 fêmeas, DZUP).

\section{Catachlorops fuscinevris (Macquart, 1838)}

Distribuição geográfica: Brasil (Minas Gerais, Espírito Santo ao Rio Grande do Sul).

Material examinado: Paraná: Ilha do Mel, Fortaleza, 20/XI/1989, R. Dutra leg. (1 fêmea, DZUP).

\section{Catachlorops muscosus (Enderlein, 1925).}

Distribuição geográfica: Brasil (Paraná, Santa Catarina, Rio Grande do Sul); Argentina (Mendoza). 
Nota: A ocorrência da espécie no estado foi registrada por Carrera \& Lane (1945), porém o material não foi encontrado na coleção Pe. Jesus Santiago Moure (DZUP) para análise.

\section{Catachlorops potator (Wiedemann, 1828)}

Distribuição geográfica: Brasil (São Paulo à Santa Catarina); Argentina (Misiones).

Material examinado: Paraná: Piraquara, XII/1944, Hatschbach leg. (1 fêmea, MZSP).

\section{Catachlorops psolopterus (Wiedemann, 1828)}

Distribuição geográfica: Brasil (Minas Gerais à Santa Catarina); Uruguai.

Material examinado: Paraná: Guaratuba, 1972, isca viva, França leg. (28 fêmeas, DZUP). Marumbi, II/1943, sem coletor (1 fêmea, DZUP)

\section{Gênero Chlorotabanus Lutz, 1913}

Espécies esverdeadas ou amarelas; olhos unicoloridos; hábitos crepusculares; fronte relativamente larga e calo frontal ausente.

\section{Chlorotabanus inanis (Fabricius, 1787)}

Distribuição geográfica: Sul do México ao Peru e Brasil (São Paulo, Paraná).

Material examinado: Paraná: Ilha do Mel, Praia Grande, 04/ XII/1988, R. Dutra leg. (1 fêmea, DZUP). Pontal do Sul, 05/XII/1992, R. Bassi leg. (1 fêmea, DZUP).

Nota: Primeiro registro no estado do Paraná.

\section{Chlorotabanus parviceps (Kröber, 1934)}

Distribuição geográfica: Guiana; Brasil (Rondônia, Rio de Janeiro, São Paulo, Paraná, Santa Catarina); Peru.

Material examinado: Paraná: Morretes, IAPAR, 26/III/1985, C.I.I.F., Luminosa (1 fêmea, DZUP).

\section{Gênero Diachlorus Osten Sacken, 1876}

Face lisa e brilhante; antena com placa basal achatada lateralmente; labela membranosa; ocelos indistintos; escleritos pleurais com pruína acinzentada; corpo amarelo ou preto; asa com mancha escura distal.

\section{Diachlorus bivittatus (Wiedemann, 1828)}

Distribuição geográfica: Brasil (Amazonas (?), Bahia (?), Mato Grosso (?), São Paulo; Paraná; Santa Catarina).

Material examinado: Paraná: Matinhos, 11/XI/1990, R. Dutra leg. (13 fêmeas, DZUP). Pontal do Sul, 06/I/1993, R. Bassi leg. (28 fêmeas, DZUP).

\section{Diachlorus distinctus Lutz, 1913}

Distribuição geográfica: Brasil (Minas Gerais, Rio de Janeiro, Paraná, Santa Catarina).

Material examinado: Paraná: Pontal do Sul, 11/XI/1992, R. Bassi leg. (11 fêmeas, DZUP).

Nota: Primeiro registro no estado do Paraná.

\section{Diachlorus flavitaenia Lutz, 1913}

Distribuição geográfica: Brasil (Mato Grosso, São Paulo à Santa Catarina); Paraguai; Argentina (Corrientes).

Material examinado: Paraná: Guaratuba, 7/II/1965, C. Dipterologia (1 fêmea, DZUP). Vila Velha, 18/II/1965, Mitchell \& Moure leg. (1 fêmea, DZUP).

\section{Gênero Dichelacera Macquart, 1838}

Calo frontal quase sempre tão largo quanto a fronte, nunca espiniforme; olhos com pelo menos uma faixa transversal; labela largamente esclerotinizada.

\section{Dichelacera alcicornis (Wiedemann, 1828)}

Distribuição geográfica: Brasil (Minas Gerais à Santa Catarina); Bolívia; Argentina (Chaco, Corrientes, Misiones).

Material examinado: Paraná: Antonina, 8/III/1983, H. Z. Fischer leg. (1 fêmea, DZUP). Caiobá, 2/II/1975, Pe. Moure \& G. Vogt leg. (1 fêmea, DZUP). Campo Largo, 08/II/1992, R. Bassi leg. (19 fêmeas, DZUP). Ilha do Mel, 05/XI/1989, R. Dutra leg. (5 fêmeas, DZUP). Fênix, Reserva Est. I.T.C.F., 08/XII/1986, Lev. Ent. PROFAUPAR, Malaise (1 fêmea, DZUP); idem, 29/XII/1986 (1 fêmea, DZUP). Foz do Iguaçu, 7/XII/1966, Exc. Dept. ZOO leg. (2 fêmeas, DZUP). Jundiaí do Sul, Fazenda Monte Verde, 27/X/1986, Lev. Ent. PROFAUPAR, Malaise (2 fêmeas, DZUP); idem, 15/XII/1986 (2 fêmeas, DZUP). Pinhais, 20/II/1992, R. Bassi leg. (23 fêmeas, DZUP). Pontal do Sul, 22/I/1993, R. Bassi leg. (2 fêmeas, DZUP).

\section{Dichelacera intermedia Lutz, 1915}

Distribuição geográfica: Brasil (Minas Gerais, São Paulo, Paraná, Santa Catarina).

Material examinado: Santa Catarina: Florianópolis, XII/1957, B. Tavares \& J. Lane leg. (2 fêmeas, MZSP).

Nota: Primeiro registro no estado do Paraná.

\section{Dichelacera januarii (Wiedemann, 1819)}

Distribuição geográfica: Brasil (Minas Gerais; Espírito Santo; São Paulo; Paraná; Santa Catarina; Rio Grande do Sul); Paraguai; Argentina (Misiones).

Material examinado: Paraná: Guaratuba, 7/II/1965, C. Dipterologia leg. (2 fêmeas, DZUP). Jundiaí do Sul, Fazenda Monte Verde, 15/ XII/1986, Lev. Ent, PROFAUPAR, Malaise (2 fêmeas, DZUP). Morretes, 2/XI/1965, F. Giacomel leg. (5 fêmeas, DZUP).

\section{Dichelacera unifasciata Macquart, 1838}

Distribuição geográfica: Brasil (São Paulo, Paraná); Bolívia; Paraguai; Argentina (Buenos Aires); Uruguai.

Material examinado: Paraná: Vila Velha, 1944, sem coletor (1 fêmea, MZSP).

\section{Gênero Dicladocera Lutz, 1913}

Dente antenal longo, probóscide curta com labela membranosa; geralmente com algumas cerdas na basicosta; olhos frequentemente pilosos; asas com padrão de colorido escuro.

\section{Dicladocera gutipennis (Wiedemann, 1828)}

Distribuição geográfica: Brasil (Mato Grosso, Minas Gerais à Santa Catarina).

Material examinado: Paraná: Morretes, Marumbi (500m), 15/VIII/1966, Laroca \& O. Mielke leg. (3 fêmeas, DZUP). Ponta Grossa, VIII/1942, sem coletor (1 fêmea, DZUP); idem, VIII/1944 (1 fêmea, DZUP).

\section{Gênero Lepiselaga Macquart, 1838}

Espécies pequenas e predominantemente escuras; palpos curtos, largos, brilhantes e achatados; tíbias acentuadamente infladas; célula discal estreitada medianamente.

\section{Lepiselaga albitarsis Barretto, 1949}

Distribuição geográfica: Brasil (Paraná); Paraguai; Argentina (Entre Rios, Chaco, Santa Fé); Uruguai.

Nota: A ocorrência da espécie no estado foi registrada por Bassi (1995), porém o material não foi encontrado na coleção Pe. Jesus Santiago Moure (DZUP) para análise.

\section{Lepiselaga crassipes (Fabricius, 1805)}

Distribuição geográfica: México; Cuba; Porto Rico; Jamaica; Colômbia; Brasil; Argentina. 
Material examinado: Paraná: Rio Paracai, I/1954, Dante \& Dionis leg. (1 fêmea, DZUP). Curitiba, IX/1961, S. Laroca leg. (1 macho, DZUP).

\section{Gênero Leucotabanus Lutz, 1913}

Fronte estreita (índice frontal geralmente maior que 4); tubérculo ocelar e ocelos vestigiais presentes; labela membranosa; basicosta com cerdas geralmente mais claras ou menos numerosas que nas adjacências da veia costa; escutelo quase sempre com pruína e cerdas claras.

\section{Leucotabanus albibasis (Brèthes, 1910)}

Distribuição geográfica: Brasil (Rio de Janeiro, São Paulo, Paraná); Argentina.

Material examinado: Paraná: Foz do Iguaçu, 7/XII/1966, D. Zoo. U.F.P. leg., lâmpada (1 fêmea, DZUP).

Nota: Primeiro registro no estado do Paraná.

\section{Leucotabanus exaestuans (Linnaeus, 1758)}

Distribuição geográfica: México; Colômbia; Trinidad; Brasil; Argentina (Salta, Chaco, Misiones).

Material examinado: Paraná: Fênix, Res. Est. I.T.C.F., 29/ XI/1986, Lev. Ent. PROFAUPAR, Lâmpada (1 fêmea, DZUP). Foz do Iguaçu, 5/XII/1966, Exc. Dept. ZOO (1 fêmea, DZUP); idem, 7/XII/1966 (1 macho, DZUP). Guaratuba, 7/II/1965, C. Dipterologia (1 fêmea, DZUP).

\section{Leucotabanus sebastianus Fairchild, 1941}

Distribuição geográfica: Brasil (Minas Gerais à Santa Catarina).

Material examinado: Paraná: Foz do Iguaçu, 7/XII/1966, D. Zoo. U.F.P. leg., lâmpada (1 fêmea, DZUP).

\section{Gênero Pachyschelomyia Barretto, 1950}

Espécies parecidas com Phaeotabanus, mas com tíbias anteriores infladas; asas escuras; calo frontal delgado.

\section{Pachyschelomyia notopleuralis Barretto, 1950}

Distribuição geográfica: Brasil (São Paulo, Paraná); Argentina (Corrientes, Misiones).

Material examinado: Paraná: Vila Velha, 06/II/1948, sem coletor (1 fêmea, DZUP).

Nota: Primeiro registro no estado do Paraná.

\section{Gênero Phaeotabanus Lutz, 1913}

Espécimes geralmente amarelados em vida; fronte geralmente estreita; calo frontal pequeno, mais ou menos arredondado na base, com projeção dorsal longa; labela parcialmente esclerotinizada; asas com padrão de colorido escuro.

\section{Phaeotabanus aphanopterus (Wiedemann, 1828)}

Distribuição geográfica: Brasil (Mato Grosso, Paraná).

Material examinado: Paraná: Foz do Iguaçu, 7/XII/1966, D. Zoo, U.F.P. leg., Lâmpada (5 fêmeas, DZUP).

\section{Phaeotabanus cajennensis (Fabricius, 1787)}

Distribuição geográfica: Colômbia; Trinidad; Guiana Francesa; Brasil (São Paulo, Paraná); Bolívia.

Material examinado: Paraná: sem localidade, 1972, França leg., isca viva (5 fêmeas).

Nota: Primeiro registro no estado do Paraná.

\section{Phaeotabanus litigiosus (Walker, 1850)}

Distribuição geográfica: Brasil (Minas Gerais, Rio de Janeiro, São Paulo, Paraná).
Material examinado: Paraná: Ilha do Mel, 18/XII/1988, R. Dutra leg. (1 fêmea, DZUP). Pontal do Sul, 06/XII/1990, R. Bassi leg. (1 fêmea, DZUP); idem, 11/XII/1990 (2 fêmeas, DZUP).

Nota: Primeiro registro no estado do Paraná.

\section{Gênero Pseudacanthocera Lutz, 1913}

Espécies semelhantes a Leucotabanus, mas com palpos inflados e brilhantes; antenas delgadas; tubérculo no vértice bem visível, com vestígios de ocelos; asas hialinas, geralmente com veia costa escura, distinta; corpo alongado.

\section{Pseudacanthocera sylveirii (Macquart, 1838)} ná).

Distribuição geográfica: Brasil (Goiás ao Rio de Janeiro, Para-

Material examinado: Paraná: Ilha do Mel, Praia Grande, 01/ I/1989, R. Dutra leg. (1 fêmea, DZUP).

Nota: Primeiro registro no estado do Paraná.

\section{Gênero Stenotabanus Lutz, 1913}

Fronte larga; calo frontal não espiniforme, geralmente tão largo quanto a fronte. Olhos com pelo menos duas faixas em vida.

\section{Stenotabanus littoralis Coscarón, 1975}

Distribuição geográfica: Sul do Brasil; Leste da Argentina.

Material examinado: Paraná: Pontal do Sul, 21/I/1993, R. Bassi leg. (1 fêmea, DZUP).

\section{Stenotabanus taeniotes (Wiedemann, 1828)}

Distribuição geográfica: Brasil (Mato Grosso, São Paulo; Paraná; Santa Catarina).

Material examinado: Paraná: Campo Largo, 25/III/1992, R. Bassi leg. (2 fêmeas, DZUP). Guaratuba, 7/II/1965, C. Dipterologia leg. (2 fêmeas). Ilha do Mel, 25/XI/1990, R. Bassi leg. (10 fêmeas, DZUP). Pinhais, 20/II/1992, R. Bassi leg. (1 fêmea, DZUP). Pontal do Sul, 15/XI/1991, R. Bassi leg. (2 fêmeas, DZUP).

\section{Gênero Stibasoma Schiner, 1867}

Espécies semelhantes a abelhas. Fronte relativamente larga; antena curta, flagelo com espinho dorsal longo; palpos inflados; tíbias infladas com franjas de cerdas longas.

\section{Stibasoma planiventre (Wiedemann, 1828)}

Distribuição geográfica: Brasil (São Paulo; Paraná; Santa Catarina).

Material examinado: Paraná: Pontal do Sul, 13/X/1992, R. Bassi leg. (1 fêmea, DZUP). Pontal do Sul, 28/X/1992, R. Bassi leg. (7 fêmeas, DZUP); idem 11/XI/1992, R. Bassi leg. (3 fêmeas, DZUP); idem 22/XII/1992 (4 fêmeas, DZUP).

\section{Stibasoma viridiventre (Macquart, 1838)}

Distribuição geográfica: Venezuela; Brasil (Minas Gerais à Santa Catarina).

Material examinado: Paraná: Caiobá, XII/1942, Hatschbach leg. (1 fêmea, MZSP).

\section{Gênero Stypommisa Enderlein, 1923}

Fronte paralela ou convergente abaixo, estreita; tubérculo e ocelos geralmente presentes; calo frontal normalmente mais estreito do que a fronte e espiniforme; na maioria das espécies, as asas apresentam manchas escuras nas veias transversais e na forquilha da veia $R_{4+5}$.

\section{Stypommisa philipi (Barretto, 1948)}

Distribuição geográfica: Brasil (Paraná) 
Material examinado: Paraná: Deodoro, Banhado, XI/1944, Hatschbach leg. (1 macho, MZSP).

\section{Stypommisa rubrithorax (Macquart, 1838)}

Distribuição geográfica: Brasil (Mato Grosso, Goiás, Minas Gerais, São Paulo, Paraná); Bolívia; Paraguai; Argentina.

Material examinado: Paraná: Pontal do Sul, 11/XI/1992, R. Bassi leg. (5 fêmeas, DZUP).

Nota: Primeiro registro no estado do Paraná.

\section{Tribo Tabanini}

Basicosta com cerdas tão densas quanto nas adjacências da veia costa; às vezes com tubérculo no vértice, mas sem vestígios de ocelos; labela sem partes esclerotinizadas.

\section{Gênero Poeciloderas Lutz, 1921}

Escapo inflado e protuso dorsalmente; asa com manchas escuras nas intersecções das veias; célula $R_{5}$ estreitada ou fechada no extremo distal.

\section{Poeciloderas quadripunctatus (Fabricius, 1805)}

Distribuição geográfica: México; Costa Rica; Panamá; Brasil; Argentina.

Material examinado: Paraná: Campo Largo, 12/II/1992, R. Bassi leg. (2 fêmeas, DZUP). Colombo, EMBRAPA, BR 476 Km 20, 22/ XII/1986, Lev. Ent. PROFAUPAR, Malaise (1 fêmea, DZUP). Foz do Iguaçu, 10/XII/1966, Exc. Dept. ZOO leg. (5 fêmeas, DZUP). Guarapuava, sem data, G. Kurowski leg. (7 fêmeas, DZUP). Jundiaí do Sul, Faz. Monte Verde, 27/X/1986, Lev. Ent. PROFAUPAR, Malaise (1 fêmea, DZUP). Ponta Grossa, XII/1939, sem coletor (1 fêmea, DZUP).

\section{Gênero Tabanus Linnaeus, 1758}

Coloração, fronte e calo frontal variáveis; ocelos quase sempre indistintos; labela membranosa; basicosta densamente recoberta de cerdas, tão densamente quanto nas adjacências da veia costa; pernas delgadas.

\section{Tabanus corpulentus Brèthes, 1910}

Distribuição geográfica: Brasil (Mato Grosso, São Paulo, Paraná); Paraguai; Argentina.

Material examinado: Paraná: Foz do Iguaçu, 3/XII/1966, Exc. Dep. ZOO (1 fêmea, DZUP); idem, 7/XII/1966 (2 fêmeas, DZUP).

\section{Tabanus fuscus Wiedemann, 1819}

Distribuição geográfica: Brasil (Bahia ao Rio Grande do Sul e Mato Grosso); Argentina (Misiones); Uruguai.

Material examinado: Paraná: Foz do Iguaçu, 15/XII/1965, L. Azevedo leg. (1 fêmea, DZUP). Morretes, 9/I/1966, Mitchell - Graf leg. (1 fêmea, DZUP). Sem localidade, 1972, França leg., isca viva (9 fêmeas, DZUP).

\section{Tabanus johannesi Fairchild, 1942}

Distribuição geográfica: Brasil (Mato Grosso, São Paulo, Paraná); Paraguai.

Material examinado: Paraná: Curitiba, XI/1959, P. D. Hurd leg. (1 macho, DZUP).

Nota: Primeiro registro no estado do Paraná.

\section{Tabanus lineola Fabricius, 1794}

Distribuição geográfica: Região Neártica; Ilhas Bahamas; Brasil (Paraná).

Material examinado: Paraná: Curitiba, XI/1929, sem coletor (1 fêmea, MZSP).

Nota: Primeiro registro no estado do Paraná.

\section{Tabanus occidentalis Linnaeus, 1758}

Distribuição geográfica: México; Cuba; Jamaica; Guatemala; Honduras; Panamá; Venezuela; Trinidad; Brasil; Argentina.

Material examinado: Paraná: Campo Largo, 09/I/1993, R. Bassi leg. (2 fêmeas, DZUP). Fênix, Res. Est. I.T.C.F., 17/XI/1986, Lev. Ent. PROFAUPAR, Malaise (1 fêmea, DZUP); idem, Res. Est. I.T.C.F., 06/IX/1986, Lev. Ent. PROFAUPAR, Lâmpada (1 fêmea, DZUP); idem, 01/X/1986 (1 macho, DZUP); idem, 05/X/1986 (1 macho, DZUP); idem, 27/III/1987 (1 macho, DZUP); idem, 28/III/1986 (1 macho, DZUP). Foz do Iguaçu, 7/XII/1966, Exc. Dept. ZOO (1 fêmea, DZUP). Jundiaí do Sul, Faz. Monte Verde, 15/XII/1986, Lev. Ent. PROFAUPAR, Malaise (1 fêmea, DZUP). Pinhais, 20/II/1992, R. Bassi leg. (5 fêmeas, DZUP). Pontal do Sul, 15/XII/1991, R. Bassi leg. (13 fêmeas, DZUP).

\section{Tabanus triangulum Wiedemann, 1828}

Distribuição geográfica: Brasil; Bolívia; Paraguai; Argentina (Buenos Aires a Salta); Uruguai.

Material examinado: Paraná: Campo Largo, 12/I/1992, R. Bassi leg. (2 fêmeas, DZUP). Foz do Iguaçu, 3/XII/1966, Exc. Dept. ZOO leg. (2 fêmeas, DZUP). Ilha do Mel, 05/X/1991, R. Bassi leg. (1 fêmea, DZUP); idem, 12/I/1992, (2 fêmeas, DZUP). Matinhos, 4/X/1967, A. B. Hanke leg. (1 fêmea, DZUP). Ponta Grossa, 14/IX/1946, sem coletor (1 fêmea, DZUP).

\section{Discussão}

Dados anteriores a este trabalho indicavam a ocorrência de 40 espécies de tabanídeos no Paraná, distribuídos em 19 gêneros (Carrera \& Lane 1945; França 1975; Fairchild \& Burger 1994; Dutra e Marinoni 1994; Bassi 1995); neste trabalho, são indicados 28 novos registros, totalizando 68 espécies e 23 gêneros ocorrentes no estado, incluindo duas subespécies. Variedades de espécies foram omitidas neste trabalho, por não representarem categorias taxonômicas válidas. No material coletado no Projeto PROFAUPAR (Marinoni \& Dutra, 1993) foram identificados sete gêneros. Este resultado pode ser atribuído ao método de coleta, utilizando armadilhas Malaise "light-weight" seguindo o modelo de Townes (1972). A armadilha Malaise é um dos melhores métodos para a coleta de tabanídeos, porém, armadilhas pequenas e leves como as utilizadas no PROFAUPAR diminuem a eficiência da coleta; armadilhas maiores, como as descritas por Gressit \& Gressit (1962) são mais eficientes para a coleta de tabanídeos. França (1975), utilizando isca viva, coletou espécies de 12 gêneros, em localidades situadas no litoral e no primeiro planalto paranaense.

\section{Agradecimentos}

Aos Professores Doutores Augusto Loureiro Henriques do INPA, Luciane Marinoni e Sionei Ricardo Bonatto da UFPR pela leitura, análise crítica e sugestões na versão anterior deste trabalho.

\section{Referências Bibliográficas}

BASSI, R.M.A. 1995. Estudios taxonómicos y ecológicos de poblaciones de tábanos (Insecta - Diptera: Tabanidae) del litoral del Estado do Paraná (Brasil), con miras a evaluar la eficiencia de diversos métodos de control biológico. Tese de doutorado, Universidad Nacional de La Plata, Argentina.

CARRERA, M. \& LANE, J. 1945. Diptera de Caiobá (Est. do Paraná) (Diptera, Stratyomiidae e Tabanidae). Arq. Mus. Paranaense, 4(5):127-136, figs.

COSCARÓN, S. \& PAPAVERO, N. 1993. An Illustrated manual for identification of the Neotropical genera and subgenera of Tabanidae (Diptera). Coleção Emilie Snethlage, Museu Paraense Emílio Goeldi, Belém.

COURI, M.S. \& PONT, A.C. 1999. A key to the world genera of the Coenosiini (Diptera, Muscidae, Coenosiinae). Stud. dipt. 6(1):93-102. 
DUTRA, R.R.C. 1993. Comparação da entomofauna de nove localidades do Estado do Paraná (Brasil), com especial referência à da Ilha do Mel (Baía de Paranaguá). Tese de doutorado, Universidade Federal do Paraná, Curitiba.

DUTRA, R.R.C. \& MARINONI, R.C. 1994. Insetos capturados com armadilha malaise na Ilha do Mel, Baía de Paranaguá, Paraná, Brasil. II. Tabanidae (Diptera). Rev. Bras. Zool. 11(2):247-256.

FAIRCHILD, G.B. 1969. Notes on Neotropical Tabanidae XII. Classification and distribution, with keys to genera and subgenera. Arq. Zool., S. Paulo 17(4):199-255.

FAIRCHILD, G.B. \& BURGER, J.F. 1994. A Catalog of the Tabanidae (Diptera) of the Americas South of the United States. Mem. Am. Entomol. Inst. 55(1):1-244.

FRANÇA, J.M. 1975. Sobre o comportamento de alguns tabanídeos do litoral e do primeiro planalto do Estado do Paraná, Brasil (Diptera, Tabanidae). Tese de mestrado, Universidade Federal do Paraná, Curitiba.

GRESSIT, J.L. \& GRESSIT, M.K. 1962. An improved Malaise trap. Pac. Insects 4(1):87-90.

KRINSKY, W.L. 1976. Animal disease agents transmitted by horse flies and deer flies (Diptera: Tabanidae). J. Med. Entomol. 13(3):225-275.
MAGNARELLI, L.A., ANDERSON, J.F. \& THORNE, J.H. 1979. Diurnal nectar-feeding of Salt Marsh Tabanidae (Diptera). Environ. Entomol. 8(3):544-548.

MARINONI, R.C. \& DUTRA, R.R.C. 1993. Levantamento da Fauna Entomológica no Estado do Paraná. I. Introdução. Situações climática e florística de oito pontos de coleta. Dados faunísticos de agosto de 1986 a julho de1987. Rev. Bras. Zool. 8(1/2/3/4):31-73[1991].

MCALPINE, J.F. 1981. Morphology and Terminology. In: Manual of Neartic Diptera (J.F. McAlpine et al. eds.). Research Branch Agriculture Canada, Ottawa, v.1, p.9-63.

PECHUMAN, L.L. \& TESKEY, H.J. 1981. Tabanidae. In: Manual of Neartic Diptera (J. F. McAlpine et al. ed.). Research Branch Agriculture Canada, Ottawa, v.1, p.464-478.

RAFAEL, J.A. \& CHARLWOOD, J.D. 1980. Idade fisiológica, variação sazonal e periodicidade diurna de quatro populações de Tabanidae (Diptera) no Campus Universitário, Manaus, Brasil. Act. Amaz. 10(4):907-927.

ROBERTS, R.H. 1967. Feeding of Horseflies (Tabanidae: Diptera) on Plant Juices. Entomol. News 78(9):250-251.

TOWNES, H. 1972. A light-weight malaise trap. Entomol. News $83: 239-247$ 